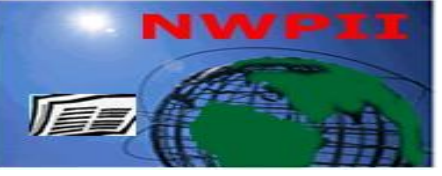

American Journal of Biomedical Sciences

ISSN: 1937-9080

nwpii.com/ajbms

\title{
Paraquat Induced Toxicity in Adrenals in Albino Mice
}

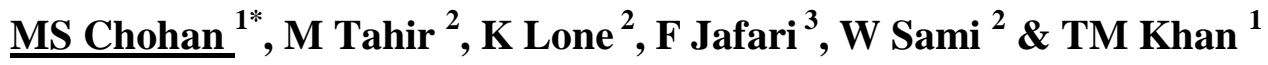 \\ ${ }^{1}$ College of Clinical Pharmacy, King Faisal University, Al-Ahsa, Kingdom of Saudi Arabia \\ ${ }^{2}$ University of Health Sciences Lahore, Pakistan \\ ${ }^{3}$ Akhtar Saeed Medical College, Bahria Town, Lahore, Pakistan \\ *Corresponding author \\ MS Chohan \\ College of Clinical Pharmacy, \\ King Faisal University, \\ P.o.Box 400, Al-Ahsa 31982 \\ Kingdom of Saudi Arabia \\ chohanshahzad@hotmail.com
}

Received: 29 December 2010; | Revised: 27 March 2011; | Accepted: 4 June 2011

\begin{abstract}
Objectives: The current study aims to observe the histological effects of paraquat on the adrenal Glands of the mice after single exposure to sub-lethal dose of the drug.

Materials and Method: Forty male mice, fifteen control (group I) and twenty-five experimental (group II) were used. Each experimental animal (group II) was given a single dose of paraquat i.e $20 \mathrm{mg} / \mathrm{kg}$ dissolved in $0.2 \mathrm{ml}$ normal saline as an intraperitoneal injection, while for the control group (I) each animal was given an equal amount of normal saline by the same route. The exposure duration for the study was comprised of ten days. On the tenth day all the animal (control and experimental) were slaughtered. Whole adrenals were removed, fixed in $10 \%$ formal saline for 48 hours and processed for routine histological studies.

Results: Histological examination of the experimental group showed that the adrenal cortical sinusoids contained large number of erythrocytes, suggesting congestion of the organ; similar changes were observed in blood vessels of medulla.

Conclusion: Findings of the current study demonstrate congestion in the sinusoids. It can be assumed that this congestion was due to the formation of peroxynitrite anion ( $\left.\mathrm{ONOO}^{-}\right)$which may have major role in the progression of the paraquat toxicity.
\end{abstract}

Keywords: Paraquat, adrenals, herbicide, adrenal toxicity, histopathology.

\section{Introduction}

Paraquat is a non-selective contact herbicide; its properties were discovered in 1955 and were registered as herbicide in 1962 by ICI laboratories
[1]. It is easily accessible to farmers in developing countries [2]. Chemically paraquat is 1, 1'dimethyl-4, 4'-bipyridinium dichloride [3]. It is available in liquid form with $\mathrm{pH}$ range of 6.5 to 7.5 and is stable in acidic/ neutral solutions. 
However, paraquat is unstable in alkaline medium [4]. Paraquat is inactive when exposed to inert clays / ionic surfactants and decomposes in the presence of ultraviolet light [4].

The acute intraperitoneal LD50 in mouse is $30 \mathrm{mg} / \mathrm{kg}$ [5]. The toxic effects of paraquat to the cells are due to the production of paraquat free radicals, after re-oxidation with oxygen molecules [6]. Studies conducted among lab animals to prove the mechanism of toxicity, it is well absorbed through the oral route and once it reaches the tissues is reduced to an unstable free radical. These free radicals are reoxidised to form cation which augment the superoxide anion. Herbicide paraquat are often reported as one the agents that may be used for suicidal attempt, in case of humans the accidental or suicidal intake of paraquat result toxic organ affects with the dose of $4 \mathrm{mg} / \mathrm{kg}$ body weight [4].

Initial work to test the toxicity of paraquat showed swelling of pneumocytes, interalveolar septa became thicker and infiltrated with lymphocytes and macrophages; pneumocytes type II showed wider channels of endoplasmic reticulum; there was localized hyperplasia of cardiac interstitial tissue, swollen mitochondria and sarcoplasmic reticulum; cerebral neurocytes showed degeneration and there was aggregation of pyramidal cells of hippocampus with their nuclei closely packed. The numbers of giant cells in spleen were reported to have increased [6]. Whereas normally, the red pulp of spleen contains few giant cells only [7]. It was observed that paraquat causes necrosis of adrenal glands [8].

However, there is limited work done to evaluate the toxic effects of paraquat on adrenal glands. The current study will focus on this neglected aspect of paraquat toxicity and will study the morphological changes in the adrenal glands after a single sublethal exposure of paraquat in albino mouse.

\section{Materials and Methods}

Forty adult male mice of BALB/c strain, weighing 30-35 grams, were used for the experiment. These animals were obtained from National Institute of Health, Islamabad and were housed in stainless steel cages (5 mice / cage) with wood shavings at the floor. They were fed on standard mouse diet and fresh tap water adlibitum, controlled room temperature $\left(25 \pm 1{ }^{\circ} \mathrm{C}\right)$, humidity (nearly $70 \%$ ) and 12 hours light and dark cycle [9].

\subsection{Experimental Design}

The animals were divided in two groups. Group A served as control and consisted of fifteen BALB/c strain. Group B was experimental and consisted of twenty-five $\mathrm{BALB} / \mathrm{c}$ strain. Each experimental animal was given a single dose (20 $\mathrm{mg} / \mathrm{kg}$ ) of paraquat dissolved in $0.2 \mathrm{ml}$ normal saline by an intraperitoneal injection, whereas each animal in control group was given an equal amount of normal saline by the same route.

The animals were sacrificed on the tenth day post-experiment. The adrenals were separated from the fascia by using blunt dissection and were removed for macroscopic examination. Whole adrenals were fixed in physiological solution (10\% saline) for 48 hours. The tissues were processed for routine histology, stained with hematoxylin and eosin and studied with light microscope (Leica DM 1000).

\subsection{Statistical Analysis}

Microscopic data are presented as percentages. These percentages were compared according to chi-square test. The difference was regarded statistically significant if the ' $p$ ' value was $<0.05$.

\section{Observations and results}

\subsection{Gross features}

On gross examination, adrenals were pyramid in shape, rose coloured and covered by a capsule; these were normal in appearance both in control and experimental groups.

\subsection{Histological features}

In histological sections of the control group, the adrenal glands were normal and all zones were at their appropriate locations (Fig.1,2,3) 


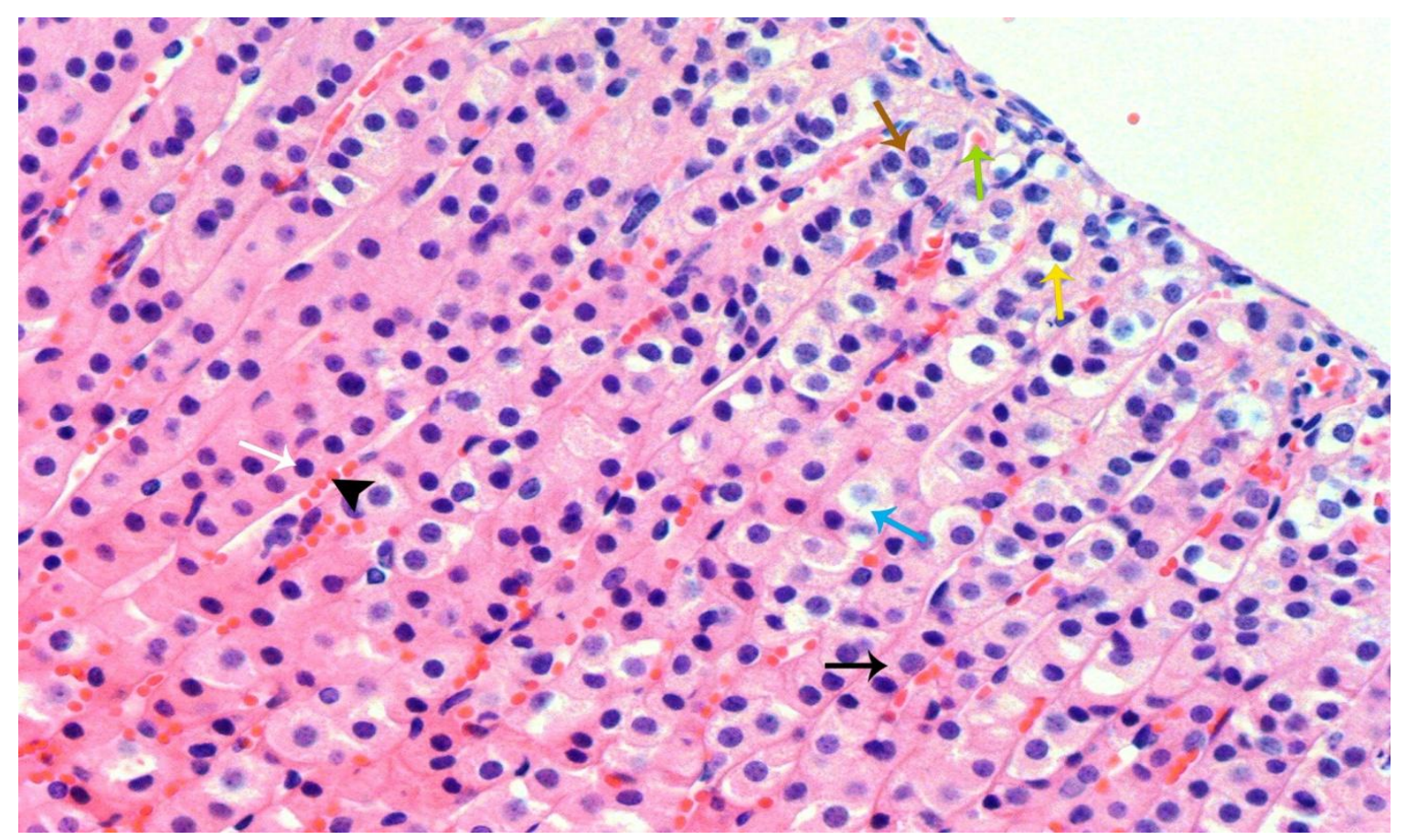

Fig.1. Photomicrograph of the adrenal gland cortex from the control group (I) showing cells in zona glomerulosa forming closely spaced arcades, have oval to rounded nuclei and acidophilic cytoplasm (brown arrow). Note the cytoplasmic vacuolation in cell cytoplasm (yellow arrow). Erythrocytes are present in sinusoids (green arrow). Note the cells in zona fasciculata arranged in columns, having rounded nuclei (white arrow) and acidophilic cytoplasm (black arrow), note the cytoplasmic vacuolation (blue arrow). Erythrocytes can be seen in the sinusoids (black arrowhead). H\&E stain. X.200

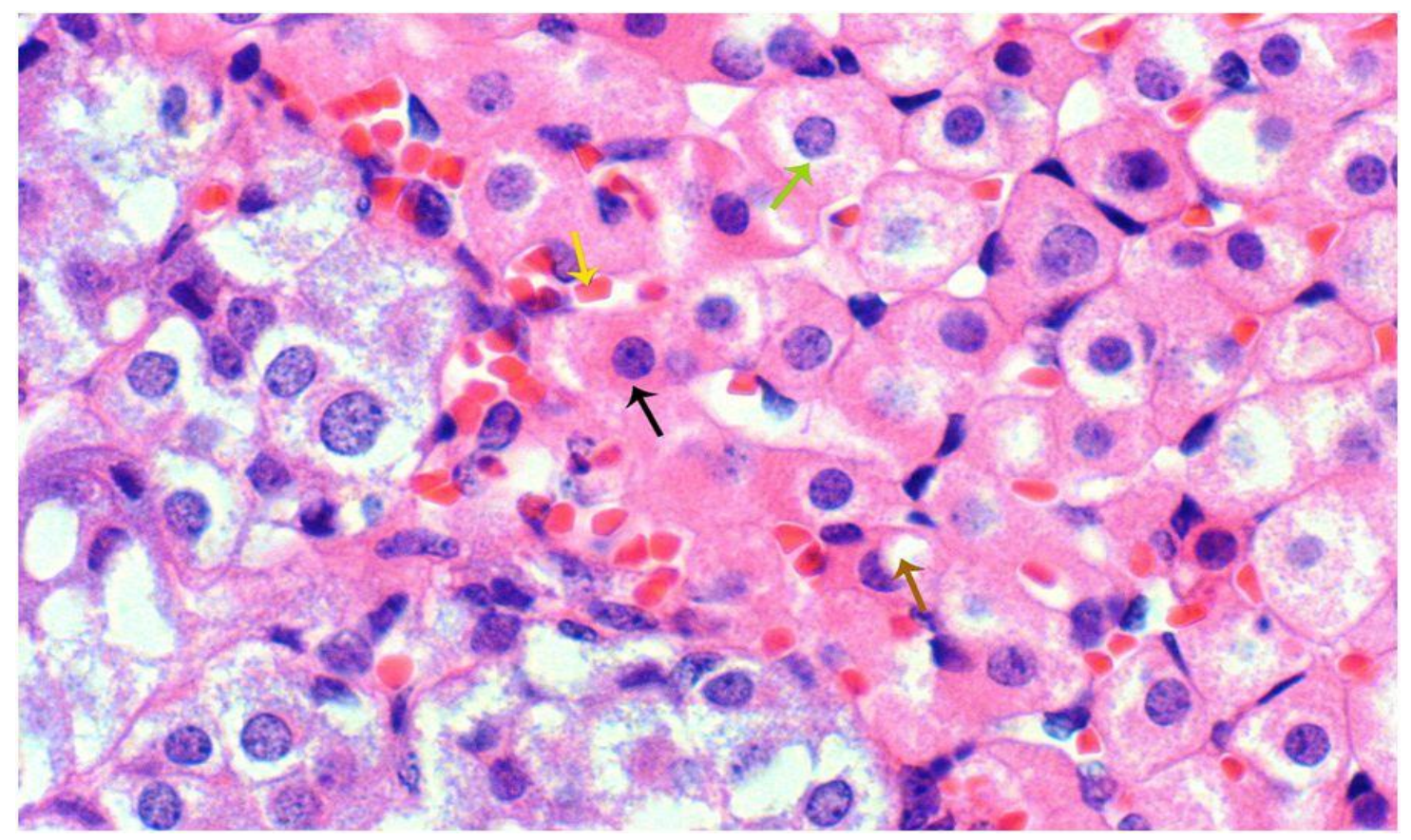

Fig.2. Photomicrograph of the adrenal gland from the control group (I) showing polyhedral cells in zona reticularis, these cells have rounded nuclei and acidophilic cytoplasm (black arrow), note the cytoplasmic vacuolation seen in these cells (brown arrow). Erythrocytes are present in the sinusoids (yellow arrow). Note the cytoplasmic vacuolation seen in cells of zona fasciculata (green arrow). H\&E stain. X400 


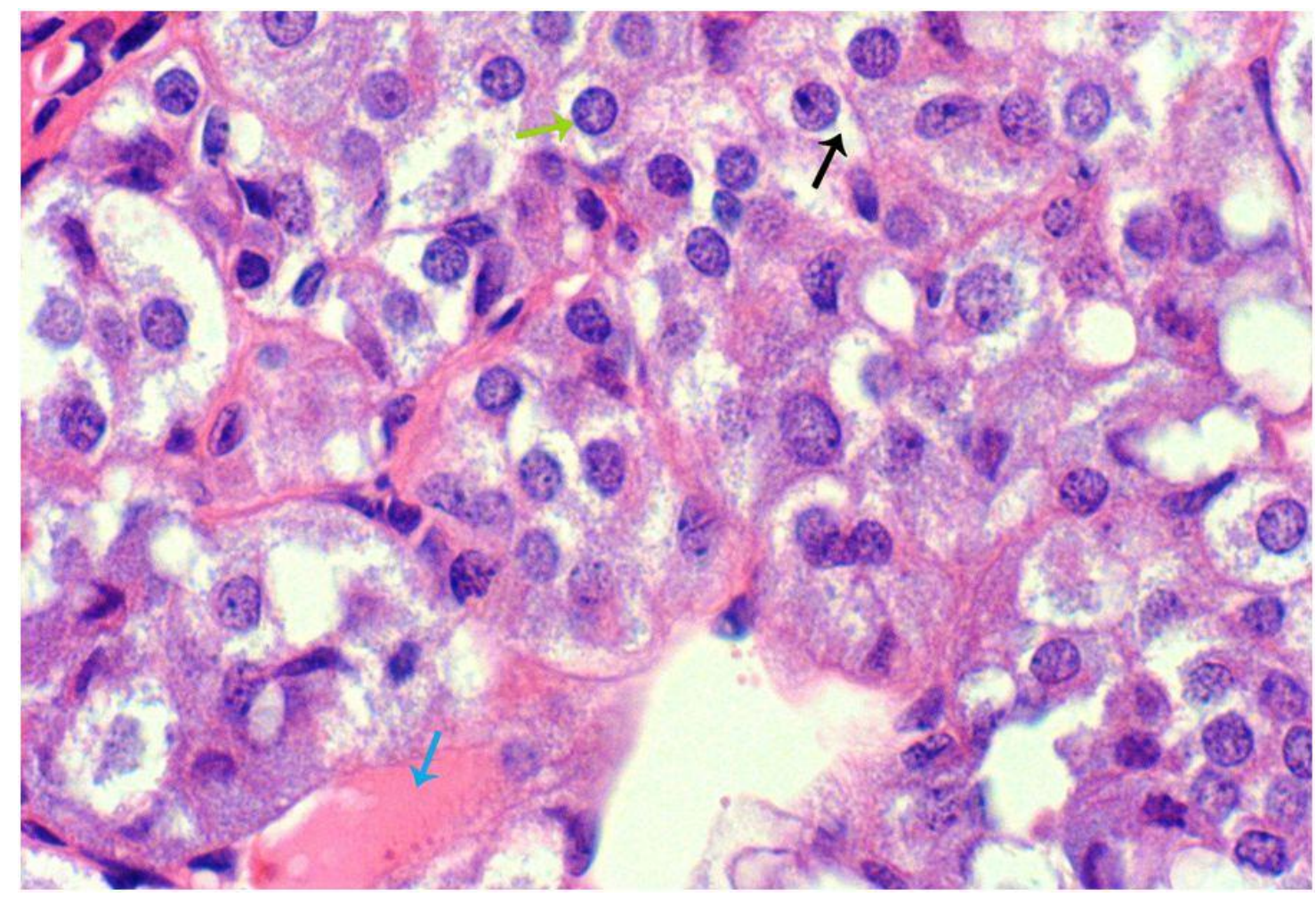

Fig.3. Photomicrograph of the adrenal gland medulla from the control group (I) showing polyhedral cells arrange in round clusters, having rounded nuclei and basophilic cytoplasm (green arrow). Note the vacuolation seen in cytoplasm of these cells (black arrow). Erythrocytes (blue arrow) are seen in the blood vessels. H\&E stain. X.400

Table 1: Comparison of congestion of blood vessels of adrenals in control and treated groups

\begin{tabular}{|l|l|l|l|l|}
\hline \multirow{2}{*}{} & \multicolumn{2}{|l|}{ Negative } & Positive \\
\cline { 2 - 5 } & $\begin{array}{l}\text { Number of } \\
\text { Animals }\end{array}$ & $\%$ & $\begin{array}{l}\text { Number of } \\
\text { Animals }\end{array}$ & $\%$ \\
\hline Control group (15) & 15 & $100 \%$ & 00 & $00 \%$ \\
\hline Treated group (25) & 01 & $4.0 \%$ & 24 & $96 \%$ \\
\hline Total & 16 & $40 \%$ & 24 & $60 \%$ \\
\hline & & & & \\
\hline
\end{tabular}

Chi-Square, $\mathrm{P}<0.001^{*}$

In histological section of treated group, most of the sinusoids present in three zones of adrenal cortex were filled with red blood cells, indicative of sign of congestion (Fig.4 and Fig.5).

Red blood cells were seen as dense collection in most of the blood vessels present in the medulla, showing sign of congestion in medulla (Fig.6). This congestion of erythrocytes was seen in $96 \%$ of animals in the treated group and statistically significant $(\mathrm{P}<0.001)$ as compared with the animals in control group (Table 1). In our work, necrosis of adrenal cells was not observed.

\section{Discussion}

Paraquat is a toxic chemical that is widely used as herbicide. There are few studies available to evaluate its adverse effects despite its extensive herbicidal use. The present study was designed to investigate its histological effects on adrenals of 
mice after giving it as a single sublethal dose by intraperitoneal injection.

Histology of adrenals in paraquat treated animals showed sign of congestion both in the adrenal cortex and medulla. According to the findings of Yokomori et al. (2001), nitric oxide (NO) can be the potential agent responsible for the increase in the size of the sinusoidal endothelial fenestrae, therefore reducing the microvascular tone of sinusoids [10]. It was reported by the previous findings of Chabot et al. (1997) that peroxynitrite can be the one of the potential agents responsible for the dilatation of the pulmonary arteries [11], which induces vasorelaxant effects and dilatation in blood vessels by reducing their tone [11]. Furthermore, Nitric oxide (NO) synthesized by the endothelial nitric oxide synthase is reported to regulate the hepatic blood flow and vascular resistance, and plays a significant role in stabilizing the microcirculation in the body [12]. However, O'Donnell and Freeman (2001) showed that superoxide $\left(\mathrm{O}^{-} 2\right)$ anions generated in paraquat treated animals, reacted with NO and yielded highly toxic peroxynitrite anion (ONOO-) [13]. Farshid et al. (2002) showed that peroxynitrite treatment intratracheally caused inflammatory changes in the respiratory tract of rabbits and produced congestion and oedema in trachea and lungs [14]. Other studies like, Day et al., (1999) reported that paraquat induced endothelial cell toxicity was attenuated by inhibitors of NO synthase, which prevented NADPH oxidation [15]. It is suggested that the congestion of blood vessels, seen in the present study, was due to endothelial cell damage, which lead to microcirculation failure and causes congestion in the adrenals.

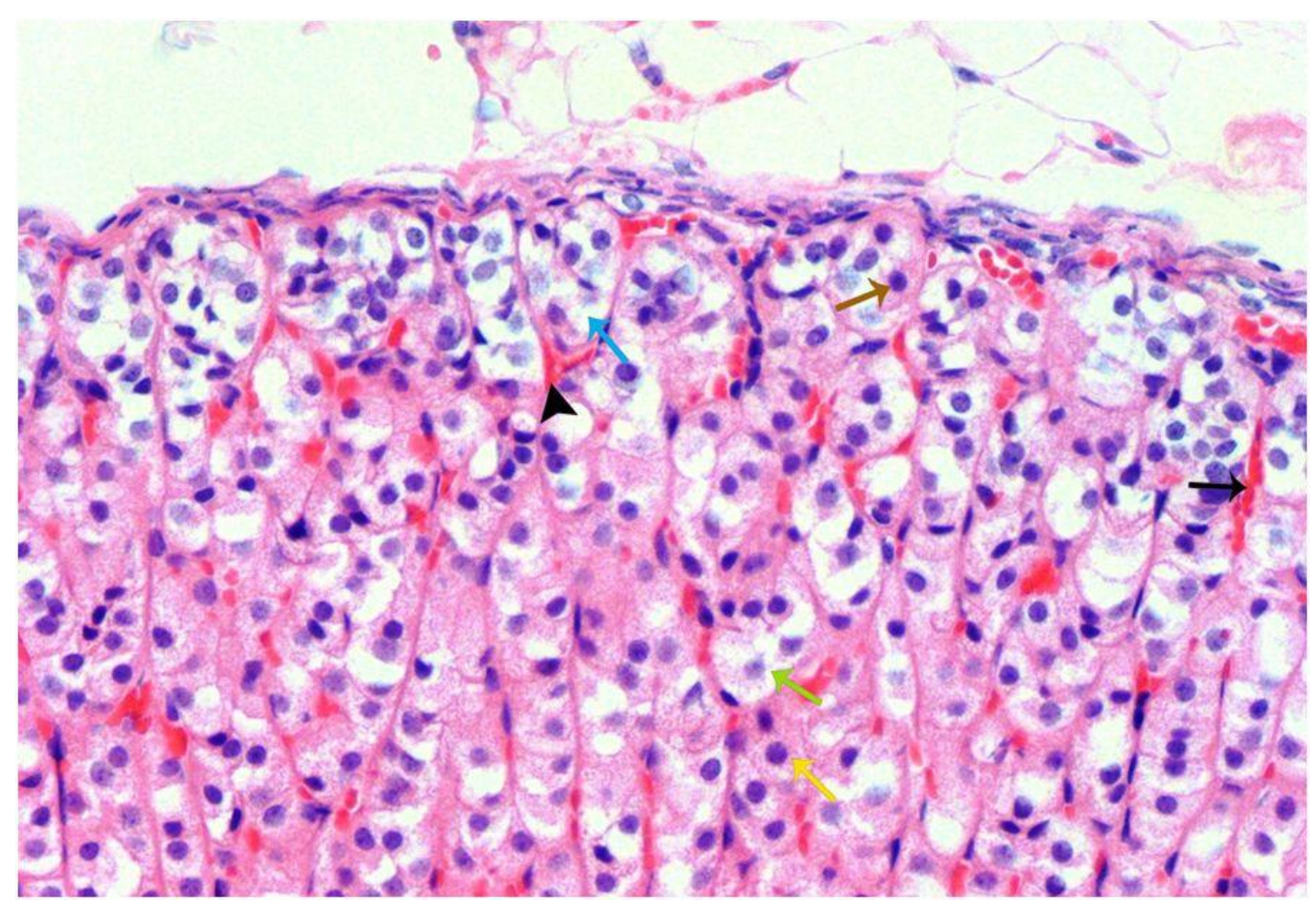

Fig.4. Photomicrograph of the adrenal cortex from the treated group (II) showing sinusoids, filled with erythrocytes (black arrowhead) in zona glomerulosa and in zona fasciculate(black arrow). The cells in zona glomerulosa have oval to round shaped nuclei and acidophilic cytoplasm (brown arrow); these cells forming closely spaced arcades. Note the cytoplasmic vacuolation seen in these cells (blue arrow). The cells, seen in zona fasciculata are arranged in long columns, having rounded nuclei and acidophilic cytoplasm (yellow arrow). Cytoplasmic vacuolation are seen in these cells (green arrow). H\&E stain. X.200 


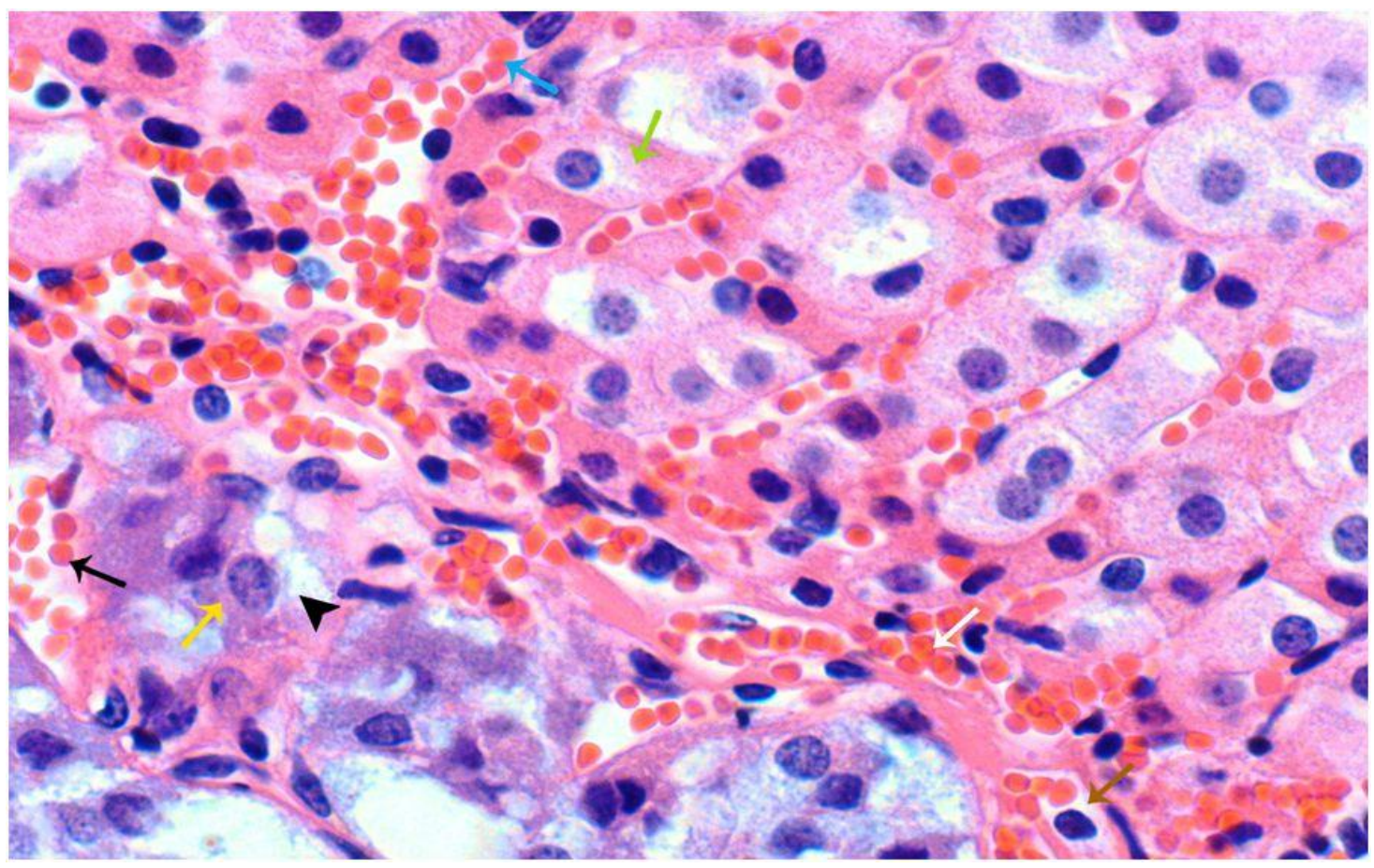

Fig.5. Photomicrograph of the adrenal gland from the treated group (II) showing, sinusoids in zona reticularis filled with erythrocytes (white arrow). Note the cytoplasmic vacuolation (brown arrow). The cells (green arrow) and sinusoids (blue arrow) in zona fasiculata. The cells seen in medulla are arranged in round clusters, having rounded nuclei and basophilic cytoplasm (yellow arrow). Note the cytoplasmic vacuolation seen in these cells (black arrow head) and blood vessels are filled with erythrocytes (black arrow). H\&E stain. X.400

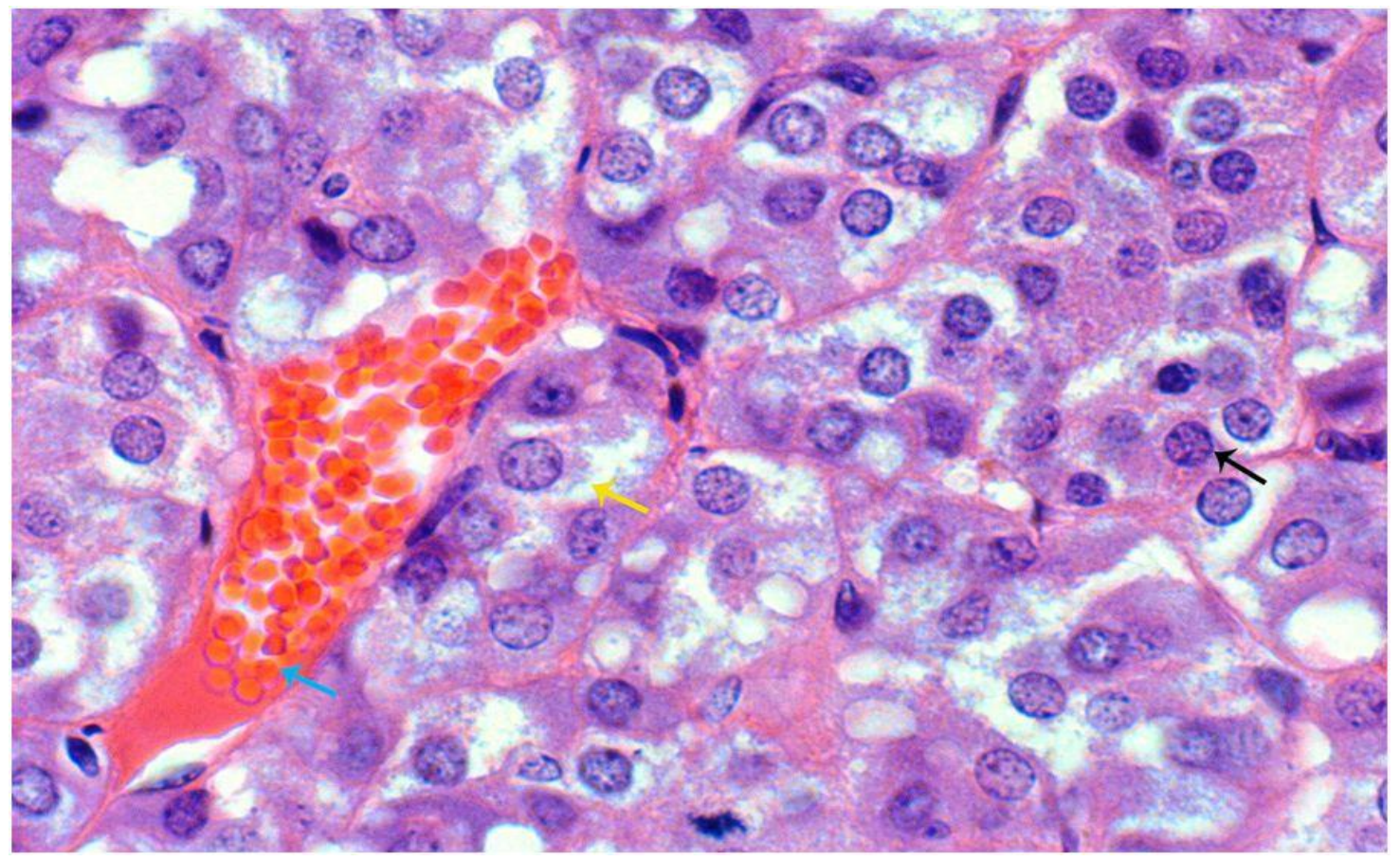

Fig.6. Photomicrograph of the adrenal gland medulla from the treated group (II) showing blood vessels filled with erythrocytes (blue arrow). Note the cells are arranged in round clusters, having rounded nuclei and basophilic cytoplasm (black arrow). Cytoplasmic vacuolation are seen in these cells (yellow arrow) H\&E stain X.400 
The present study showed the cytoplasmic vacuolation in cells of adrenal gland both in control and in treated group (Figs 2 and 5.). Bancroft and Gamble (2002), reported that in routine method of fixation, using formaldehyde containing fixatives, lipids are largely lost from the cells that contain lipids [16]. Therefore, it was thought that these cytoplasmic vacuolation seen in the present study were due to comparable reasons.

\section{Conclusion}

Findings of the current study demonstrate congestion in the sinusoids. It can be assumed that this congestion was due to the formation of peroxynitrite anion $\left(\mathrm{ONOO}^{-}\right)$which may have major role in the progression of the paraquat toxicity.

\section{Recommendations}

Paraquat is one of the frequently used herbicide among most the South Asian and south East Asian nations. In a recent survey conducted revealed the poor knowledge and information among the herbicide distributors and farmers on the paraquat use and sale [17]. The finding of this survey reported that the dealers were unable to interpret the information mention in the pictogram on the herbicide container [17]; they just know that this is dangerous and the use of the Personal Protective Equipments (PPEs) by the farmers is limited. The findings of this study are of great worth to the agriculture and public health department in order to educate the farmers and herbicide dealer about the safety concerns of paraquat use and disposal. Furthermore, authorities should ensure that all the companies manufacturing paraquat should provide the safety manual with the product and only registered dealers should be allowed to sell such products. Such initiative will be helpful in preventing the paraquat toxicity events.

\section{References}

1- Paraquat- Monograph [online]. Published 2003 [Cited 2005]. Available from: http://www.panap.net/docs/monos/paraquatSe p03.pdf

2- Wesseling, C., Joode, BW., Ruepert, C., Leon, C., Monge, P., Hermosillo, H., and Partanen, T. Paraquat in developing country. Occup. Environ. Health 2001.

3- Roberts, T.R., Dyson, J.S., and Lane, M.C. Deactivation of the Biological Activity of Paraquat in the Soil Environment: a Review of Long-Term Environmental Fate. J. Agri. Food. Chem. 2002, 50, 3623-3631. doi:10.1021/jf011323x

4- Ashton, C., and Leahy, N. Paraquat [online]. Published 2000 [Cited 2005]. Available from:http://www.inchem.org/documents/pims /chemical/pim399.htm\#SectionTitle:7.2\%20 \%20Toxicology.

5- Kegley, S., Hill, B., Orme, S. PAN Pesticide Database, Pesticide Action Network [online]. Published 2007 [Cited 2007]. Available from: http:www.pesticideinfo.org.

6- Luty, S., Latuszynska, J., Halliop, J., Tochman, A., Obuchowska, D., Korczak, B., Przylepa, E., and Bychawski, E. Dermal toxicity of paraquat. Ann. agric. environ. Med. 1997, 4, 217-227.

7- Ussing., Baelde., Larsen, O., Naeser., Prause., and Bruijn. Haematopathology of SjogrenMice: Histopathological Changes in Spleens After Semiallogeneic Cell Transfer. Scandinavian Journal of Immunology. 1999, 49, 641-648. doi:10.1046/j.13653083.1999.00548.x

8- Nagi AH. 1970. Paraquat and adrenal cortical necrosis. $\mathrm{Br}$ Med J. 2(5710): 669. doi:10.1136/bmj.2.5710.669-b

9- Mustafa, A., Gado, A.M., Al-Shabanah, O.A., and Al-Bekairi, A.M. Protective effect of aminoguanidine against Paraquat-induced oxidative stress in the lung of mice. Toxicology and pharmacology. 2002, 132, 391-397.

10- Yokomori, H., Oda, M., Ogi, M., Kamegaya, Y., Tsukada, N., and Ishii, H. Endothelial nitric oxide synthase and caveolin-1 are co- 
localized in sinusoidal endothelial fenestrae. Liver 2001,.21, 198-206. doi:10.1034/j.16000676.2001.021003198.x

11- Chabot, F., Mitchell, J.A., Quinlan, G.J., and Evans, T.W.Characterization of the vasodilator properties of peroxynitrite on rat pulmonary artery: role of poly (adenosine 5'diphosphoribose) synthase. Br. J. Pharmacol. 1997, 121， 485-490. PMid:9179390 doi:10.1038/sj.bjp.0701162

12- Stvrtinova, V., Jakubovsky, J., Ivan, H. Inflammation and fever [online]. Published 1995 [Cited 2006].Available from: http://www.savba.sk/logos/books/scientific/In ffever.html

13- O'Donnell, V.B., and Freeman, B.A. Interactions between nitric oxide and lipid oxidation pathways: implications for vascular disease. Circ. Res. 2001. 19, 12-21.
14- Farshid, A.A., Sadeghi-Hashjin, G., and Ferdowsi, H.R. Histopathological studies on the effects of peroxynitrite on the lungs and trachea of rabbits. Eur. Respir. J. 2002, 20, 1014-16. doi:10.1183/09031936.02.00264102

15- Day, B.J., Patel, M., Calavetta, L., Chang, L.Y., and Stamler, J.S. A mechanism of paraquat toxicity involving nitric oxide synthase. Medical Sciences. 1999, 96, 12760 12765.

16- Bancroft, J.D., and Gamble, M. Theory and Practice of Histological Techniques. $5^{\text {th }}$ ed. Edinburgh: 2002, Churchill Livingstone.

17- Barbara Dinham. Pesticide users at risk Published by the Berne Declaration, May 2007. 6-10. http://www.evb.ch/cm_data/ Paraquat-Code_Survey_FINAL_rev1.pdf 